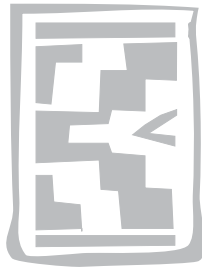

\title{
Field experiences with early pregnancy diagnosis by progesterone-based ELISA in sows
}

\author{
M.H. BOMA and G. BILKEI* \\ Veterinary Consulting, Bahnhofstrasse 42, CH - 8600 Dübendorf, Switzerland
}

\begin{abstract}
BOMA, M.H. \& BILKEI, G. 2008. Field experiences with early pregnancy diagnosis by progesteronebased ELISA in sows. Onderstepoort Journal of Veterinary Research, 75:55-58

In four Kenyan pig breeding units the pregnancy diagnosis of sows has been carried out in two groups: Group 1 ( $n=1911)$ : the sows were transrectaly pregnancy tested between Days 17-22 postmating by ultrasound. Sows testing non-pregnant immediately received one dose of $400 \mathrm{IU}$ pregnant mare serum gonadotropin (PMSG) (equine chorion gonadotropin, eCG) and 200 IU human chorion gonadotropin (hCG). On showing signs of oestrous, the animals were subsequently artificially inseminated (AI). Group $2(n=1923)$ : sows were pregnancy tested by serum progesterone (P4)-based enzyme-linked immunosorbent assay (ELISA) on Day 17 post-breeding. P4 concentrations were categorized as positive $(>5 \mathrm{ng} / \mathrm{m} \ell)$ or negative $(<5 \mathrm{ng} / \mathrm{m} \ell)$. Sows testing nonpregnant immediately received one dose of 400 IU PMSG and 200 IU hCG by injection, and were subsequently artificially inseminated.

The following parameters were evaluated: sows diagnosed non-pregnant, days from first post-weaning insemination until the sows were inseminated at their first return to oestrus; farrowing rate and total piglets born and number of live-born piglets in litters.

The percentage of sows diagnosed non-pregnant in the two groups, as well as the totals of born piglets and of live-born piglets in litters did not differ significantly between the two groups. The number of days from the first post-weaning mating until the sows were artificially inseminated at their first return to oestrus and the administration of eCG and hCG was shorter $(P<0.01)$ and farrowing rate was higher $(P<0.01)$ in the ELISA-tested sows.
\end{abstract}

Keywords: Farrowing rate, litter size, pregnancy, sow

\section{INTRODUCTION}

Productivity in a pig breeding unit is highly dependant upon the non-productive days (NPD), which are markedly influenced by early and accurate pregnancy diagnosis (Bichard 1983). Non-productive days can be broken down into three major categories (Dial, Mars, Polson \& Vaillancourt 1992) as pre-

* Author to whom correspondence is to be directed. E-mail: bilkei.consulting @gmx.net

Accepted for publication 10 October 2007-Editor service, post-service and removing intervals. Postservice intervals include the days between mating and the detection of non pregnant sow.

Post-service intervals belong to the highly significant $(P<0.01)$ leading parts of the NPD (Polson, Dial \& Marsh 1990). In order to increase reproductive performance of the sows and the profitability and productivity of a pig breeding unit, sows should be tested for pregnancy at the earliest possible time after mating (Bilkei 1995). This, and prompt rebreeding are of the outmost economic importance 
(Krüger \& Bilkei 2002). Pregnancy has traditionally been confirmed by the absence of oestrus at 21-45 days post mating (PM) (Polson, Dial \& Marsh 1990). Plonait \& Bickhardt (1997) and Krüger \& Bilkei, (2002) summarised the "up to day" pregnancy testing methods as follows:

- Determination of the early pregnancy factor in plasma (between Day 2 of gestation until parturition),

- Determination of prostaglandin F $2 \alpha$ in plasma (Days 13-15 post-mating [PM])

- Determination of progesterone in plasma or faeces (Days 17-24 PM)

- Visible oestrous signs (at any time PM)

- Determination of oestronsulphat in plasma, faeces or urine (Days 25-35 PM)

- Vaginal biopsy (Days 30-90 PM)

- Rectal pregnancy diagnosis (from Day 30 PM)

- Instrumental pregnancy diagnosis (Kauffold \& Richter 1997) by doppler, amplitude-depth or real time (RTU) modes. The first two ultrasonic modes are mainly limited to diagnosing pregnancy $>25$ days PM. In contrast, RTU mode, although requiring experience and feeling (Krüger \& Bilkei 2002), is accurate and sensitive for diagnosing pregnancy between Days 17-25 PM.

\section{MATERIAL AND METHODS}

The present trial was carried out in four Kenyan pig production units, comprising a total of $3834 \mathrm{~F} 1$ Large White $x$ Landrace sows, mated to Large White or Duroc boars. The sows were uniformly weaned at 3 weeks of lactation $(21.1 \pm 1,2$ days during the trial period).

\section{Feeding and management}

From weaning to standing heat, a commercial lactation diet containing digestible energy (DE) 12.6 megajoul (MJ) per $\mathrm{kg}$, crude protein $180 \mathrm{~g} / \mathrm{kg}$, lysine $12 \mathrm{~g} / \mathrm{kg}$, calcium $8.5 \mathrm{~g} / \mathrm{kg}$ and phosphorus $6.5 \mathrm{~g} / \mathrm{kg}$, was provided ad libitum and was top-dressed with 300 IU vitamin E per $\mathrm{kg}$ feed. For the first 12 days after insemination, the lactation ration was fed at 2 $\mathrm{kg}$ per sow per day. Between Days 12 and 90 of gestation, the sows were fed, according to their body condition, $2-2.5 \mathrm{~kg}$ daily of a commercial gestation diet containing DE $12.2 \mathrm{MJ} / \mathrm{kg}$, crude protein $125 \mathrm{~g} / \mathrm{kg}$, lysine $6.5 \mathrm{~g} / \mathrm{kg}$, calcium $8.5 \mathrm{~g} / \mathrm{kg}$, and phosphorus $6 \mathrm{~g} / \mathrm{kg}$.

\section{Oestrus detection and artificial insemination (Al) in eros centre}

After weaning the sows were placed in the eros centre (Molnar \& Bilkei 2003). Signs regarded as indications of impending oestrus included sow behaviour, vocalization, nibbling and nosing with a boar or sows standing in adjacent crates, and reddening and swelling of the vulva, which are not always present in older sows. A positive "riding test" and slight sticky vaginal discharge (positive thumb test) were considered as final confirmations of oestrus.

The sows were artificially inseminated at their first postweaning oestrus. Semen for Al was stored at $18^{\circ} \mathrm{C}$ until used. Unused semen was discarded $48 \mathrm{~h}$ after collection. Inseminations were heterospermic and sires were equally represented among the two treatment groups (see below). All the sows were bred every $12 \mathrm{~h}$ from onset of standing heat for as many times as they would stand when teased. All inseminations were subjectively judged to be acceptable when the sow remained immobile and there was a good catheter lock, good semen uptake and minimal semen backflow following insemination. The few sows failing to meet these criteria were removed from the study. The animals received identical post insemination handling, i.e. mixing and moving into pens of 5-10 females after positive pregnancy testing, with no further regrouping until farrowing.

Between November 2005 and November 2006, the pregnancy diagnosis of the sows was carried out in two randomly selected groups as follows:

\section{Group 1 (1911 sows)}

The sows were tested for pregnancy by transrectal examination from Days 17-22 PM by using an Aloka $500 \mathrm{~V}$ ultrasound (Aloka Co. Tokyo, Japan) with 5.0 and $7.5 \mathrm{MHz}$ linear-array transducers fitted to fixed angle PVC adapters (transrectal stabilizing rod). The ultrasound testing was performed on the sows while they were kept in crates. The adapter was lubricated with obstetrical lubricant and inserted with a rotating motion into the rectum. Pregnancy was confirmed by visualizing embryonic vesicles, embryos or corpora lutea. Those sows testing non-pregnant immediately received one dose of $400 \mathrm{IU}$ pregnant mare serum gonadotropin (PMSG, equine chorion gonadotropin, eCG) and 200 IU human chorion gonadotropin (hCG) (PG 600® Intervet, Munich, Germany) by intramuscular injection. On showing oestrous signs, the animals were artificially inseminated subsequently on 3 consecutive days. 
Group 2 (1 923 sows)

The sows were tested for pregnancy by serum progesterone (P4)-based enzyme linked immunosorbent assay (ELISA, BioMetallics, Princeton, New Yersey, USA) on Day 17 PM. The ELISAs were performed at room temperature according to the manufacturer's instructions. P4 concentrations were categorized as high ( $>5 \mathrm{ng} / \mathrm{m} \ell$, positive) or low $(<5$ $\mathrm{ng} / \mathrm{m} \ell$, negative). Sows testing non-pregnant immediately received an identical dose of $P G 600 \AA$ by intramuscular injection, as those in Group 1. On showing signs of oestrus they were artificially inseminated on 3 consecutive days, similar to the sows in Group 1.

The sensitivity (97\%) of the ELISA kit and ultrasound was defined as the number of pregnant sows diagnosed correctly / total number of pregnant sows. Their specificity $(89 \%)$ was calculated as the number of non-pregnant sows diagnosed correctly / total number of non-pregnant sows. The predictive value of a positive result was defined as the probability that pregnancy exists in sows diagnosed as pregnant and the efficiency or accuracy was defined as the number of sows diagnosed correctly, either pregnant or non-pregnant / the total sows diagnosed.

The following parameters were evaluated:

A: Percentage of sows diagnosed non-pregnant in a group

B: Days from first post-weaning insemination until the sows were inseminated on their first return to oestrus following a negative pregnancy diagnosis and administration of $P G 600 \AA$

C: Farrowing rate of sows after their return to oestrus, following a negative pregnancy diagnosis and administration of PG $600 \AA$

D: Totals of born piglets and number of live-born piglets in litters of sows after the sows' return to oestrus, following a negative pregnancy diagnosis and administration of $P G 600 \AA$

\section{Calculations and statistical analysis}

Statistical analyses of the data of sows were performed using the GLM procedures of SAS ${ }^{\circ} 1999$ (SAS Institute, Cary, North Carolina) to derive leastsquares means and SE. Differences between calculated parameters (FR, subsequent total and liveborn litter size) of the groups were compared using $\chi^{2}$ test. When marked deviation from normality was present (verified by Levene's test significance), the data were transformed to homogenize such variations. The class included in the model was parity and the dependent variables were subsequent totals of born piglets and live-born piglets in litters. The month of weaning was found to be significant $(P=0.04)$ and was therefore included as a covariate. Full lactation length, full litter size suckled, numbers of piglets removed, and numbers of piglets remaining with the sows had no significant effects on subsequent totals of born piglets in the litters, and were not included as covariates. Farrowing rates were compared by $\chi^{2}$ analysis. Body condition score and number of anestrous sows in each treatment group were not statistically analysed.

\section{RESULTS AND DISCUSSION}

The percentages of sows diagnosed as non-pregnant in the two groups did not differ significantly. The days from first post-weaning breeding until the sows were inseminated on their first return to oestrus was shorter $(P<0.01)$ and the farrowing rate was higher $(P<0.01)$ in Group 2 sows. Totals of born piglets and live-born piglets in litters of sows after their return to oestrus following negative pregnancy diagnosis and administration of eCG and hCG did not differ significantly between the two groups (Table 1).

Serum concentration of progesterone is high ( $>5$ $\mathrm{ng} / \mathrm{m} \ell)$ in pregnant and low $(<5 \mathrm{ng} / \mathrm{m} \ell)$ in non-pregnant sows. The optimal time to obtain blood samples for progesterone determination is Day $17 \mathrm{PM}$ (Bilkei 1995). A study using progesterone for pregnancy diagnosis showed a sensitivity greater than $96 \%$ but specificity ranged from $80-90 \%$ (Bilkei 1995). In the present trial the sensitivity and specificity reached higher values $(97 \%$ and $89 \%$, respectively). Bilkei (1995) found false positive test results in sows with irregular return to oestrus, pseudopregnancy, or cystic ovaries but false negative results occurred only as a result of human errors in the laboratory.

Commercial ELISA-based assays have been developed for on farm application. P4 production is present throughout gestation. P4 based-ELISA pregnancy diagnosis has successively been used in sows (Glossop, Foulkes, Withworth \& Cornwell 1989). Non-return to oestrus and ultrasound diagnosis can also successfully diagnose pregnancy thus diminishing the diagnostic usefulness of the P4-based ELISA. However, P4-based ELISA is able to confirm pregnancy days before the earliest possible pregnancy diagnosis by ultrasound. Diagnosing nonpregnancy on Day 17 PM offers the unique possibil- 
TABLE 1 The results of transrectally real time ultrasonography (RTU) and progesterone-based enzyme-linked immunosorbent assay (ELISA) testing of sows in the two groups:

- Group 1 (1 911 sows): the sows were transrectaly pregnancy tested at Days 17-22 post-mating by RTU

- Group 2 (1 923 sows): sows were pregnancy tested by serum progesterone based ELISA on Day 17 post-mating

\begin{tabular}{|l|l|l|l|l|l|}
\hline Group & $\begin{array}{l}\mathbf{n} / \% \\
\mathbf{n} / \%\end{array}$ & $\begin{array}{l}\text { B } \\
\text { Days } \pm \text { SE }\end{array}$ & $\begin{array}{l}\mathbf{C} \\
\mathbf{n} / \%\end{array}$ & $\begin{array}{l}\mathbf{D} \\
\mathbf{n} \pm \mathbf{S E}\end{array}$ & $\begin{array}{l}\mathbf{E} \\
\mathbf{n} \pm \mathbf{S E}\end{array}$ \\
\hline $1: n=1911$ & $178 / 9.3 \mathrm{~ns}$ & $27.21 \pm 3.3 \mathrm{a}$ & $159 / 89.3 \mathrm{a}$ & $10.9 \pm 0.5 \mathrm{~ns}$ & $10.1 \pm 0.4 \mathrm{~ns}$ \\
$2: n=1923$ & $187 / 9.7 \mathrm{~ns}$ & $22.01 \pm 1.1 \mathrm{~b}$ & $141 / 75.4 \mathrm{~b}$ & $10.8 \pm 0.6 \mathrm{~ns}$ & $10.1 \pm 0.5 \mathrm{~ns}$ \\
\hline
\end{tabular}

ns The difference in a column is non-significant

$\mathrm{a}, \mathrm{b} \quad$ The difference in a column is significant $(P<0.01)$

A Percentage of sows diagnosed non-pregnant in a group

B Days from first post-weaning mating until the sows were artificially inseminated on their return to oestrus following negative pregnancy diagnosis and administration of $P G 600 \AA$

C Farrowing rate of sows after their return to oestrus following negative pregnancy diagnosis and application of $P G 600 \AA$

D Total of born piglets in litters

E Total of live-born piglets in litters of sows after their return to oestrus following negative pregnancy diagnosis and administration of $P G 600 \AA$

ity to support early gonadotropin secretion of the sow by injecting exogenous gonadotropin.

The ELISA kit used in this study clearly distinguished between pregnant and non-pregnant sows. P4-based ELISA is a cheap and non-labour intensive test. In the present study the 5 days shortening of NPD is a considerable cost reduction. The necessity of collecting blood is the only hindrance for ELISA-based pregnancy testing.

It is concluded that testing the serum concentration of progesterone $(>5 \mathrm{ng} / \mathrm{m} \ell$ ) is a reliable and economically feasable method of pregnancy diagnosis in sows. Because ELISA testing for serum progesterone can increase productivity and profitability in breeding units, it is a worthy method for consideration for early pregnancy diagnosis of sows.

\section{REFERENCES}

BICHARD, M. 1983. Litter size and sow productivity, in New developments in scientific breeding, No. 3, Farnham Royal England: Commonwealth Agricultural Bureaux. Pig Improvement Supplement.

BILKEI, G. 1995. Herd health strategy for improving the reproductive performance of pigs. Proceedings of the $8^{\text {th }}$ "In-be- tween" Symposium of the International Society for Animal Hygiene. Hungarian Veterinary Journal, 10:766-768.

DIAL, G.D., MARSH, W.E., POLSON, D.D. \& VAILLANCOURT, J.P. 1992. Reproductive failure: differential diagnosis, in Diseases of swine, $7^{\text {th }}$ ed., edited by A.D. Leman, B.E. Straw, W.L. Mengeling, S.D. D`Allaire \& D.J. Taylor. London: Wolfe Publishing.

GLOSSOP, C.E., FOULKES, J.A., WHITWORTH, A. \& CORNWELL, E. 1989. Use of an on-farm progesterone assay kit to determine pregnancy in sows. Veterinary Record, 124:115117.

KAUFFOLD, J. \& RICHTER, A. 1997. Two years of ultrasonography in swine gynecology-experiences. Reproduction in Domestic Animals, 32:115.

KRÜGER, D. \& BILKEI, G. 2002. Comparison of efficacy and costs between real time ultrasonography (RTU) and gonadotropin estimation for pregnancy diagnosis. Pig Journal, 50: 92-102.

MOLNAR, G.B. \& BILKEI. G. 2003. Effect of modified eros centre on some reproductive parameters of the sow. Reproduction in Domestic Animals, 38:236-238.

PLONAIT, H. \& BICKHARDT, K. 1997. Gynekologische Untersuchung der Sau, in Lehrbuch der Schweinkrankheiten, $2^{\text {nd }}$ ed., edited by H. Plonait \& K. Bickhardt. Berlin: Parey Publishing.

POLSON, D.D., DIAL, G. \& MARSH, W. 1990. A biological and financial characterisation of nonproductive days. Proceedings of the $13^{\text {th }}$ International Pig Veterinary Society Congress, Lausanne: 372. 